\title{
Enzymatic fuel cells for electric power generation from domestic wastewater
}

\author{
M. S. Kiliç ${ }^{1}$, S. Korkut ${ }^{2} \&$ B. Hazer ${ }^{1}$ \\ ${ }^{I}$ Department of Chemistry, Bulent Ecevit University, Turkey \\ ${ }^{2}$ Department of Environmental Engineering, Bulent Ecevit University, \\ Turkey
}

\begin{abstract}
Enzymatic biofuel cells (EFCs), which employ enzymes as a catalyst, convert the chemical energy released from the enzymatic oxidation of fuel into electrical energy. While chemical energy is being generated by the oxidation of fuel with enzymes, electricity is generated simultaneously by the movement of electrons released as a consequence of this chemical reaction from anode through cathode in enzymatic fuel cells. The major problem encountered in EFC studies is the difficult/slow electron transfer between the enzyme and the electrode. To mediate the electron transfer between the enzyme and the electrode's surface, low molecular weight redox compounds called mediators are used in EFC. Higher power generation and minimal interference effects at a lower cell potential are achieved by using a mediator in EFC. The scope of this study is for the development of an enhanced electron transferred EFC with a proper mediator for the generation of electrical energy by the oxidation of glucose in domestic wastewater. Therefore, glucose in domestic wastewater is utilised for energy generation. In this study, Polypyrrole-2-carboxyclic acid was modified with various mediators such as, ferrocene, neutral red and $p$-benzoquinone, which were tested for this purpose. The maximum power density $\left(100 \mathrm{nW} / \mathrm{cm}^{2}\right)$ was observed for the ferrocene modified electrodes including glucose oxidase and laccase as anodic and cathodic enzyme, respectively. The electrode fabrication step was optimized with respect to the electrode material, its operational potential and the thickness of the polymeric film. The highest current values were obtained from the addition of $10 \mathrm{mM}$ of glucose for the EFC system designed with the gold electrode material and operated with a working potential of $0.45 \mathrm{~V}$. The most suitable polymeric film thickness was achieved in the cyclic voltammetry parameters set up with a scan rate of $50 \mathrm{mV} / \mathrm{s}$ and 25 cycles. The
\end{abstract}


optimized EFC was tested in the domestic wastewater of Zonguldak City in Turkey. Ferrocene mediated EFC yielded a power density of $50-200 \mathrm{nW} / \mathrm{cm}^{2}$ for the domestic wastewater.

Keywords: pyrrole-2-carboxylic acid, enzymatic fuel cell, glucose oxidase, laccase, glucose, fuel.

\section{Introduction}

Enzyme based biofuel cells that directly convert chemicals such as glucose into electrical energy have received considerable interest in recent decades [1]. The generated output power is high enough to supply micro and mini-scale electronic systems such as small sensor-transmitter systems, microdevices and pacemakers that require relatively low power [2]. The transfer of electrons between the redox site of the enzyme and the electrode surface in fuel cells is of paramount importance. Recently, chemically synthesized polymers, conductive polymers, sol-gels, metal oxides, self-assembled monolayers and nanocomposites, along with different biomolecule immobilization strategies and polymer modifications have been used to achieve enhanced electron transfer rate [3]. Conducting polymers such as polypyrrole, polythiophene, and polyaniline have been studied in recent years mainly because of a variety of applications found for these materials in enzymatic fuel cells (EFC) and sensors [4]. Polypyrrole-2-carboxylic acid has proved to be an electroactive material with interesting properties for use in EFC.

To mediate the electron transfer between the enzyme and the electrode surface, low molecular weight redox compounds called mediators have been adsorbed or entrapped into the polymeric films [5]. Higher power generation and minimal interference effects at a lower cell potential are achieved by using a mediator in fuel cell systems. A mediator should posses the following characteristics: fast electrochemical kinetics and oxidation states that do not interfere with the enzyme and chemical stability. Also, by choosing a mediator that has a potential close to that of the fuel increases the power density [6]. A redox mediator of appropriate redox potential is required to shuttle electrons between the enzyme and electrode surface, because direct electron transfer to buried redox sites within these enzymes is generally not possible given the distance of the active site form the electrode surface [7]. Ferrocene and its derivatives have been a popular choice to use as a mediator since they fulfill most of the requirements in redox-enzyme catalysis $[3,8]$.

In this work, we report on the studies of a compartmentless EFC using Polypyrrole-2-carboxylic acid film including ferrocene as a mediator and including anodic enzyme glucose oxidase and cathodic enzyme laccase. The fabrication step and operational conditions were optimized to achieve maximum power generation for the proposed EFC. Polypyrrole-2-carboxylic acid/Ferrocene-based working electrodes were tested by using glucose as fuel. The experiments were then conducted by using glucose in domestic wastewater to generate electrical power. 


\section{Material and methods}

\subsection{Reagents}

Pyrrole-2-carboxylic acid, Acetonitrile ( $\geq 99 \%$ GC grade), $p$-benzoquinone, neutral red, Glucose oxidase from Aspergillus niger (GOx) (10 KU), Laccase from Trametes versicolor (LAC) $(\geq 10 \mathrm{U})$, Bilirubin oxidase (BOD) from Myrothecium verrucaria (25 U), N-(3-Dimethylaminopropyl)-N'ethylcarbodiimide hydrochloride (EDC) and N-Hydroxysuccinimide (NHS), were obtained from Sigma-Aldrich. Ferrocene, Sodium hydroxide, hydrochloric acid, potassium di-hydrogen phosphate and di-potassium hydrogen phosphate were purchased from Merck. Tetrabutyl ammonium tetrafluoroborate (TBAFB) and glucose monohydrate was supplied from Fluka and Riedel, respectively. Stock solutions of enzymes and glucose were prepared daily in $100 \mathrm{mM} \mathrm{pH} 5$ citrate buffers.

\subsection{Apparatus and electrochemical measurements}

Fuel cell experiments were performed by using a CHI 1040B Model electrochemical analyzer. Gold $(\varnothing=2 \mathrm{~mm})$ working electrode, Platinum wire counter electrode, $\mathrm{Ag} / \mathrm{AgCl}(3 \mathrm{M} \mathrm{NaCl}), \mathrm{Ag} / \mathrm{Ag}^{+}\left(10 \mathrm{mM} \mathrm{AgNO}_{3}\right)$ reference electrodes and a conventional electrochemical cell obtained from the same firm. Electrochemical measurements were carried out in an aerated $100 \mathrm{mM}, \mathrm{pH} 5$ citrate buffer solution with an applied potential of $-0.15 \mathrm{~V}$ for anode and $+0.3 \mathrm{~V}$ for the cathode by using four-electrode compartmentless cell, which was then waited for, to reach a steady-state current value. Various concentrations of glucose (30-50-100-300 mM) were successively added to the buffer solution to produce current-time recordings for both the anode and cathode side of the EFC system.

\subsection{Preparation of optimized EFC electrodes}

The electrode fabrication step was preceded by a cleaning phase of the gold electrode surface using gamma alumina powder then rinsed with distilled water. Ferrocene modified polypyrrole-2-carboxylic film was formed on gold anode and cathode electrochemically in polymerization medium containing $20 \mathrm{mM}$ TBAFB as a supporting electrolyte, $10 \mathrm{mM}$ ferrocene and $10 \mathrm{mM}$ pyrrole-2-carboxylic in $10 \mathrm{~mL}$ of acetonitrile at a potential scan ranging between 0 and $1.3 \mathrm{~V}$ with a scan rate of $0.05 \mathrm{~V} \mathrm{~s}^{-1}$. Carboxyl groups of polypyrrole-2-carboxylic were activated with carbodiimide solution comprised of $40 \mathrm{mM}$ EDC and $20 \mathrm{mM}$ NHS. The electrodes were washed with distilled water then $5 \mu \mathrm{L}$ of GOx $(40 \mathrm{mg} / \mathrm{mL})$ and $5 \mu \mathrm{L}$ of LAC $(40 \mathrm{mg} / \mathrm{mL})$ were dropped onto the polymeric film coated anode and cathode, respectively. The electrodes were allowed to dry and were then left for 2 hours at room temperature, for enzyme immobilization to occur. 


\section{Results and discussion}

\subsection{Selection of suitable mediator for EFC system}

Firstly, a cyclic voltammogram study of tested mediators was conducted to determine the redox potential of the mediators, thus the operating potential of the EFC system (Figure 1). The electropolymerization of the pyrrole-2-carboxylic acid/mediator film was prepared with different mediators (ferrocene, $p$-benzoquinone and neutral red) as described in Section 2.3. Electrochemical measurements were carried out at an operating potential of $-0.15 \mathrm{~V}$ anode and $+0.3 \mathrm{~V}$ cathode for ferrocene, $-0.3 \mathrm{~V}$ anode and $+0.59 \mathrm{~V}$ cathode for $\mathrm{p}$ benzoquinone and $-0.53 \mathrm{~V}$ anode and $+0.59 \mathrm{~V}$ cathode for neutral red modified electrodes.

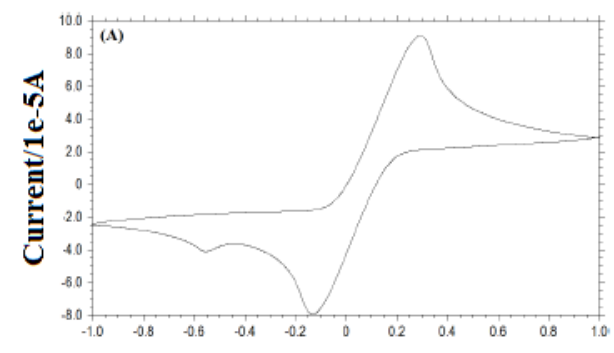

Time/s

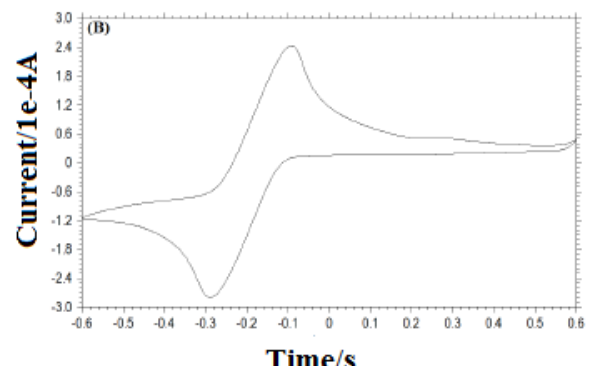

Time/s

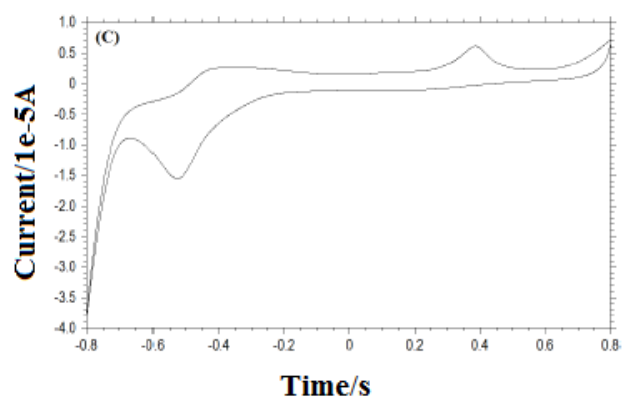

Figure 1: Cyclic voltammogram of ferrocene (A), p-benzoquinone (B), neutral red $(\mathrm{C})$ in acetonitrile at a scan rate of $0.1 \mathrm{~V} / \mathrm{s}$. 
After applying the suitable operational potential to the system, we waited for it to reach a steady-state current value under the constant stirring of citrate buffer. Then, various concentrations of glucose ranging between 30 and $300 \mathrm{mM}$ were added successively to the citrate buffer to produce current-time recordings for both the anode and cathode side of the EFC system (Figure 2). It is clearly shown in Figure 2 that ferrocene modified polypyrrole-2-carboxylic film showed the highest current values over all the others. Therefore, ferrocene modified polypyrrole-2-carboxylic acid film was coated onto the working electrode for further experiments under the cell potential of $+0.45 \mathrm{~V}(-0.15 \mathrm{~V}$ for anode and $+0.3 \mathrm{~V}$ for cathode (Figure 1A)).
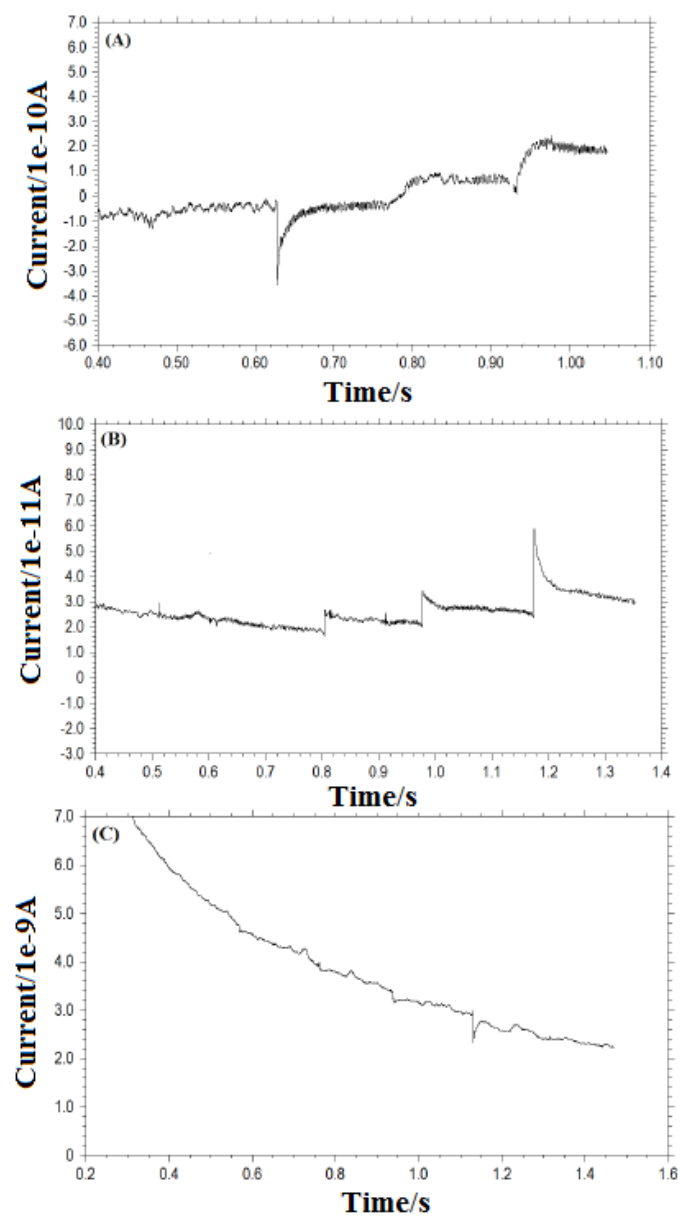

Figure 2: Current-time recording of polypyrrole-2-carboxylic acid/ferrocene (A), polypyrrole-2-carboxylic acid/ $p$-benzoquinone (B), polypyrrole-2- carboxylic acid/neutral red (C) coated cathode. 


\subsection{Selection of the cathodic enzyme}

It is known that, both BOD and GOx show efficient activity at the same $\mathrm{pH}$ level around 7 [9]. Nevertheless, BOD activity can be lower in comparison to LAC activity when the operating conditions were optimized for both of them [10]. Therefore, LAC had been selected as the cathodic enzymes in most of the EFC studies [11-14]. From this viewpoint, LAC or BOD enzymes were tested for the cathode side of the EFC system to get maximum energy generation from the system. For this purpose, two fuel cell systems including LAC or BOD were fabricated with the same fabrication procedure, as explained in the following: EFC systems including GOx anode and LAC or BOD cathode were coated, using gold electrode, according to the procedure given in Section 2.3. EFC systems were operated in $10 \mathrm{~mL}$ of $100 \mathrm{mM} \mathrm{pH} 5$ citrate buffer for the system including LAC cathode and $10 \mathrm{~mL}$ of $100 \mathrm{mM} \mathrm{pH} 7.4$ phosphate buffer for the system including BOD cathode. The potentials of $-0.15 \mathrm{~V}$ anode, $+0.3 \mathrm{~V}$ cathode for LAC, $-0.15 \mathrm{~V}$ anode and $+0.36 \mathrm{~V}$ cathode for BOD were applied. Various concentrations of glucose ranging between 30 and $600 \mathrm{mM}$ were added successively to the electrochemical cell to produce current-time recordings for both EFC systems (Figure 3). It can be observed in Figure 3A that higher, stable and increasing proportional cathodic currents versus increasing glucose concentrations were produced from the EFC including LAC cathode, in comparison to the system including BOD cathode. Therefore, LAC was selected as the cathodic enzyme for the proposed EFC.
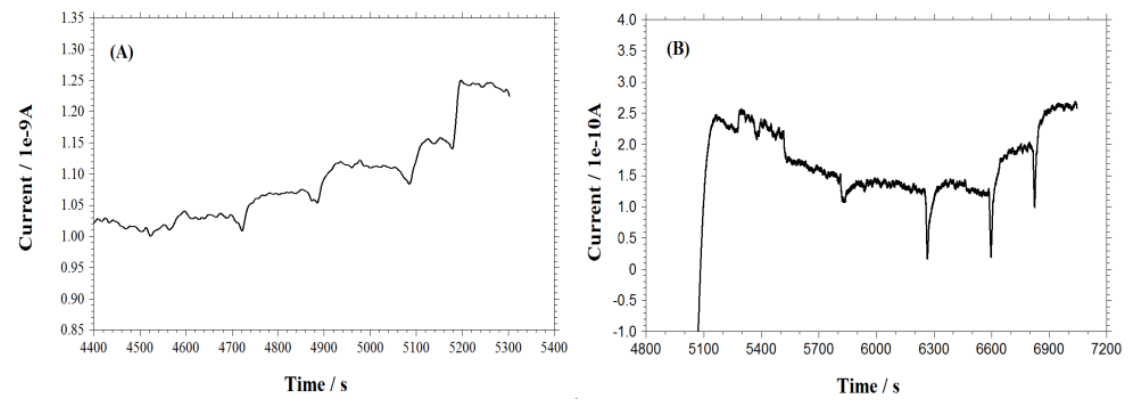

Figure 3: Current time records of polypyrrole-2-carboxylic acid/ferrocene/LAC (A), polypyrrole-2-carboxylic acid/ferrocene/BOD (B) cathode.

\subsection{Selection of electrode material}

Biofuel cells generally involve complex arrangements of immobilization polymers, redox mediators, and enzymes that must easily interact and conform to electrode material. We investigated the effect of glassy carbon and gold electrode material on EFC performance. EFC systems including GOx anode and LAC cathode were prepared using both glassy carbon and gold electrode, and the 
successive addition of various glucose concentrations were conducted at an applied potential of $-0.15 \mathrm{~V}$ for anode and $+0.3 \mathrm{~V}$ for cathode, as described previously. The current generation of the EFC prepared with gold electrode presented in Figure 3A was compared with the glassy carbon electrode result, as shown in Figure 4.

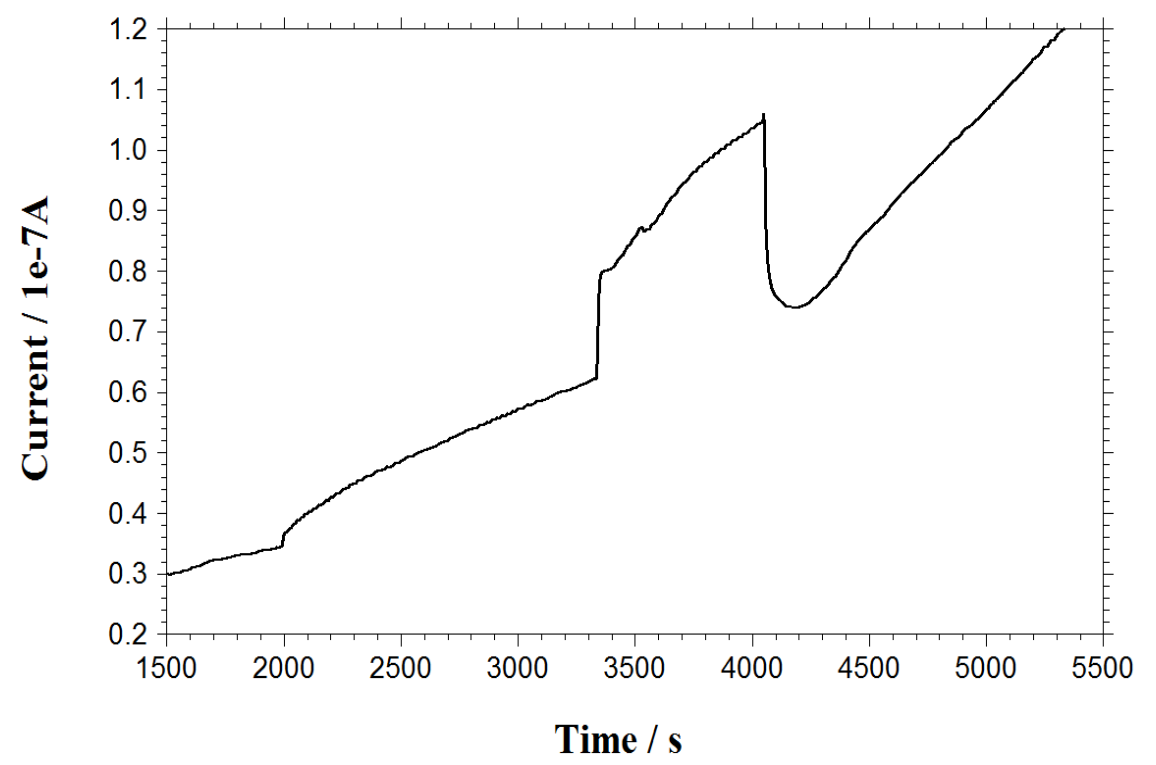

Figure 4: Current time records of polypyrrole-2-carboxylic acid/ferrocene/LAC biofilm coated on glassy carbon electrode material.

\subsection{Optimization of the polymer film thickness}

Increasing film thickness leads to the decrease of electron transferring rate between the electrode and the enzyme since it creates a barrier for mass transfer. Therefore, the thickness of the polymeric film should be optimized to acquire maximum power from the system. Pyrrole-2-carboxylic acid/ferrocene was electropolymerized on gold electrodes by changing the polymerization time. The cyclic voltammetry method was used by changing the cycle number (5-12-25-37 cycle) of the electropolymerization process. Each of the EFC systems were tested by the addition of $10 \mathrm{mM}$ glucose to the reaction medium at an applied potential of $-0.15 \mathrm{~V}$ for anode and $+0.3 \mathrm{~V}$ for cathode. Figure 5 shows the current values of the anodic and cathodic side. It is obvious from Figure 5 that the highest current was obtained from the system with the electrodes electropolymerizated with a cycle number of 25 . 

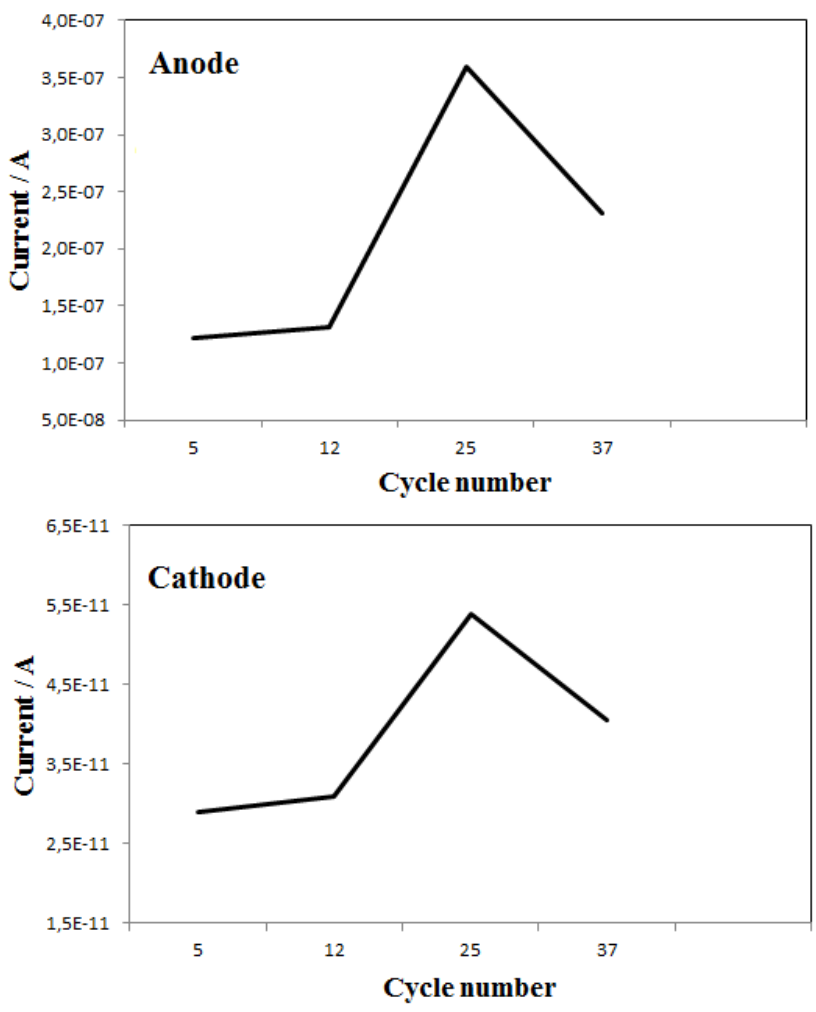

Figure 5: Current generation of EFCs prepared with different film thickness.

\subsection{Optimization of immobilized enzyme quantity}

The immobilized enzyme amount was optimized by dropping 5-10-20-30 and $50 \mu \mathrm{L}$ of $\mathrm{GOx}(40 \mathrm{mg} / \mathrm{mL})$ and LAC $(40 \mathrm{mg} / \mathrm{mL})$ enzyme solution (40-100-120-200-280-400 $\mu \mathrm{g}$ enzyme) onto the polymer film coated anode and cathode, respectively. Six EFC systems including various amounts of enzyme were prepared in this way. The EFC systems were tested by adding $10 \mathrm{mM}$ of glucose into the cell, including $100 \mathrm{mM}$, pH 5 aerated citrate buffer solution at an applied potential of $-0.15 \mathrm{~V}$ for anode and $+0.3 \mathrm{~V}$ for cathode, with continuous stirring. The cathodic currents obtained from the EFC series are presented in Figure 6. The results show that the cathodic current increased with the enzyme loading and reached the maximum when the dropped LAC amount was $200 \mu \mathrm{g}$ and when the current decreased to an enzyme amount that was higher than $200 \mu \mathrm{g}$, which was due to the saturation of enzyme active centers with glucose at the tested glucose concentration level. Therefore there is no need to use excessive amounts of cathodic enzyme for the proposed system. Similar results were obtained for the anodic enzyme (not shown). 


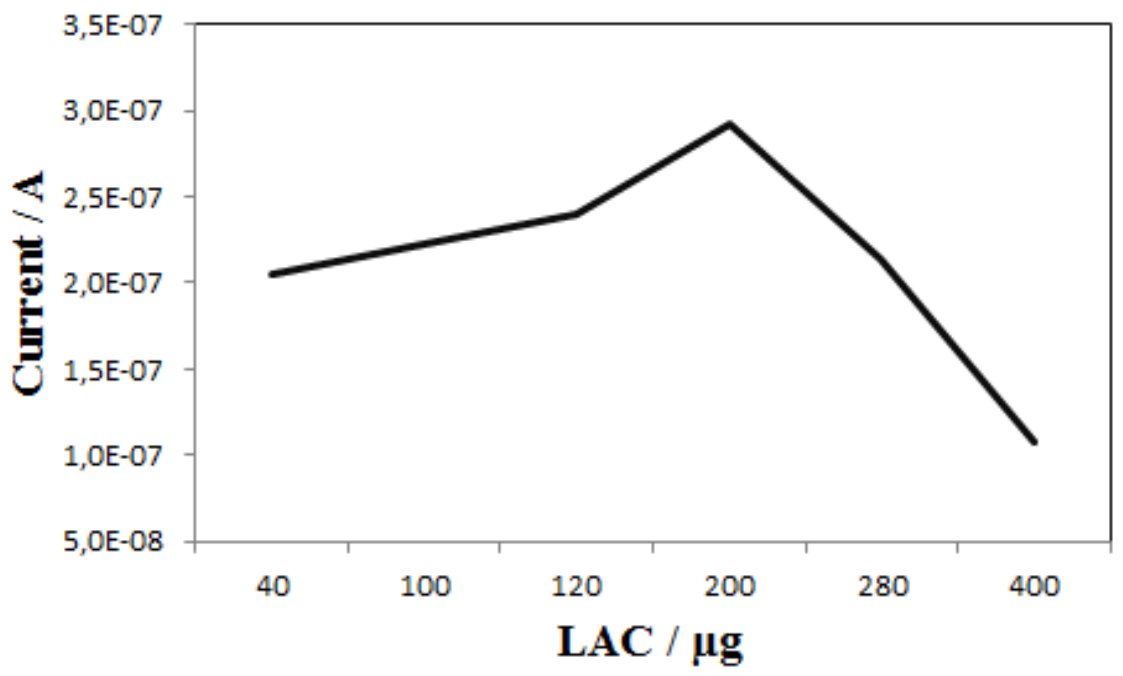

Figure 6: $\quad$ Effect of enzyme amount on current generation.

\subsection{Power generation of the EFC from domestic wastewater of Zonguldak City}

EFC systems for which the performance was optimized and developed were tested by adding $30 \mathrm{mM}$ of standard glucose into the cell, including $100 \mathrm{mM}, \mathrm{pH}$ 5 aerated citrate buffer solution at an applied potential of $-0.15 \mathrm{~V}$ for anode and $+0.3 \mathrm{~V}$ for cathode, whilst stirring continuously. The current generation through the cathode side is presented in Figure 7. The power density was calculated using the formula of $\mathrm{P}=\mathrm{I} \times \mathrm{V}\left(\mathrm{P}\right.$ : power density-nW/cm${ }^{2}$, I: current density- $\mathrm{nA} / \mathrm{cm}^{2}$, $\mathrm{V}$ : cell potential-V). The generated power density from $30 \mathrm{mM}$ of glucose addition was calculated to be $200 \mathrm{nW} / \mathrm{cm}^{2}$.

Glucose in wastewaters can be thought of as a potential fuel for EFCs. Therefore, the available glucose content can be evaluated besides treatment and discharge of wastewaters. For this purpose, inflow wastewaters were collected from the Activated Sludge Treatment Plant of Zonguldak City in Turkey. The sample was filtered using a cellulose-acetate membrane $(0.45 \mu \mathrm{m})$ filter and the suspended solids were removed. The EFC system was then operated in the same reaction medium and conditions by adding the filtered wastewater sample. The generated power density from glucose found in the sample was calculated to be $89 \mathrm{nW} / \mathrm{cm}^{2}$. It was not surprising that power generation obtained from the wastewater sample would be lower than the power obtained from standard glucose. Because wastewater includes various kinds of metabolities, ions beside glucose, there might be interference effects. In addition to this, enzymatic activity might be slowed down due to these materials. 


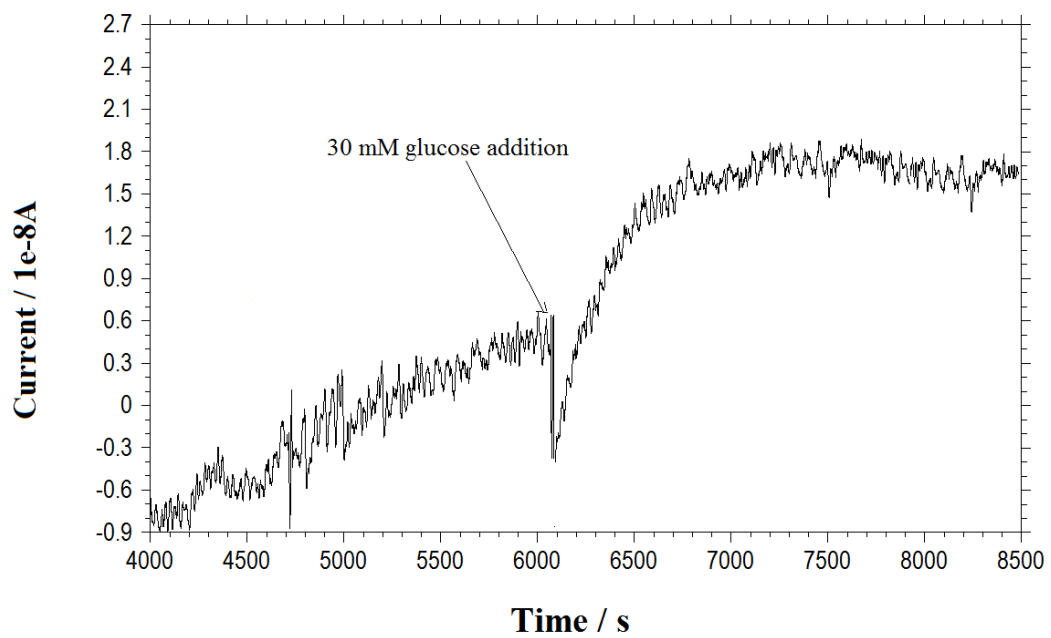

Figure 7: $\quad$ Current flow through the cathode side by the addition of standard glucose into the reaction medium.

\section{Acknowledgement}

This work was financially supported by "The Scientific \& Technological Research Council of Turkey" (TUBITAK) (Grant no. 112Y100).

\section{References}

[1] Ammam, M. \& J. Fransaer, Combination of laccase and catalase in construction of $\mathrm{H}_{2} \mathrm{O}_{2}-\mathrm{O}_{2}$ based biocathode for applications in glucose biofuel cells. Biosensor and Bioelectronics, 39(1), pp. 274-281, 2013.

[2] Brunel, L., Denele, J., Servat, K., Kokoh, K.B., Jolivalt, C., Innocent, C., Cretin, M., Rolland, M. \& Tingry, S., Oxygen transport through laccase biocathodes for a membrane-less glucose $/ \mathrm{O}_{2}$ biofuel cell. Electrochemistry Communications, 9(2), pp. 331-336, 2007.

[3] Palomera, N., José, L., Vera, C., Meléndez, E., Jaime, E., Ramirez-Vick, Tomar, M.S., Arya, S.K. \& Surinder, P.S., Redox active poly(pyrrole-Nferrocene-pyrrole) copolymer based mediator-less biosensors. Journal of Electroanalytical Chemistry, 658, pp. 33-37, 2011.

[4] Foschini, M., Silva, H.S., Silva, R.A., Marletta, A. \& Goncalves, D., Theoretical and experimental studies on the electronic, optical, and structural properties of poly-pyrrole-2-carboxylic acid films. Chemical Physics, 425, pp. 91-95, 2013.

[5] Ardhaoui, M., Zheng, M., Pulpytel, J., Dowling, D., Jolivalt, C. \& Khonsari, F.A., Plasma functionalized carbon electrode for laccasecatalyzed oxygen reduction by direct electron transfer. Bioelectrochemistry, 91, pp. 52-61, 2013. 
[6] Pas, L., Alternative energy: Enzyme-based biofuel cells. Basic Biotechnology eJournal, 3, pp. 93-97, 2007.

[7] Barriere, F., Ferry, Y., Rochefort, D. \& Leech, D., Targetting redox polymers as mediators for laccase oxygen reduction in a membrane-less biofuel cell. Electrochemistry Communications, 6, pp. 237-241, 2004.

[8] Dursun, F., Korkut O.S., Demirci, A., Gorur, M., Yilmaz, F. \& Erhan, E., Vinylferrocene copolymers based biosensors for phenol derivatives. Journal of Chemical Technology and Biotechnology, 87, pp. 95-104, 2012.

[9] Mano, N., Mao, F., Shin, W., Chen, T. \& Heller, A., Miniature biofuel cell operating at 0.78 V. Chemical Communications, 7, pp. 518-519, 2003.

[10] Osman, M.H., Shah A.A. \& Walsh, F.C., Recent progress and continuing challenges in bio-fuel cells. Part I: Enzymatic cells. Biosensors and Bioelectronics, 26, pp. 3087-3102, 2011.

[11] Barrière, F., Kavanagh, P. \& Leech, D., A laccase-glucose oxidase biofuel cell prototype operating in a physiological buffer. Electrochimica Acta, 51, pp. 5187-5192, 2006.

[12] Gupta, G., Lau, C., Branch, B., Rajendran, V., Ivnitski, D. \& Atanassov, P., Direct bio-electrocatalysis by multi-copper oxidases: Gas-diffusion laccase-catalyzed cathodes for biofuel cells. Electrochimica Acta, 56, pp. 10767-10771, 2011.

[13] Stolarczyk, K., Sepelowska, M., Lyp, D., Żelechowska, K., Jan, F. B., Rogalski, J., Farmer, K.D., Roberts, K.N. \& Bilewicz, R., Hybrid biobattery based on arylated carbon nanotubes and laccase. Bioelectrochemistry, 87, pp. 154-163, 2012.

[14] Smolander, M., Boer, H., Valkiainen, M., Roozeman, R., Bergelin, M., Eriksson, J-E., Zhang, X-C., Koivula, A. \& Viikari, L., Development of a printable laccase-based biocathode for fuel cell applications. Enzyme and Microbial Technology, 43, pp. 93-102, 2008. 